\title{
РАЗНООБРАЗНЫЕ ПОСОБИЯ И МАТЕРИАЛЫ ДЛЯ ПОСТАНОВКИ ЗВУКОВ У ВОСПИТАННИКОВ СТАРШЕГО ДОШКОЛЬНОГО ВОЗРАСТА С ТЯЖЕЛЫМИ НАРУШЕНИЯМИ РЕЧИ
}

\author{
Цырендоржиева Долгор Цыденовна \\ Шипнягова Ольга Васильевна \\ Научный руководитель: Соломинская Марина Николаевна \\ МБДОУ «Детский сад № 153»
}

\begin{abstract}
Аннотация: Данная статья о коррекционно-развивающей работе учителя-логопеда в условиях детского сада представляет собой авторскую идею использования нетрадиционных средств и методов коррекции звукопроизношения у детей дошкольного возраста. Модель построена на основе анализа научных исследований в области коррекционной педагогики и логопедии, многолетнего собственного опыта и представляет собой целостный подход к организации процесса коррекции звукопроизношения у детей дошкольного возраста.
\end{abstract}

Ключевые слова: нарушения речи, пособия, материалы, средства, методы и приемы коррекции звукопроизношения, нетрадиционные технологии.

\section{VARIOUS MANUALS AND MATERIALS FOR PRODUCING SOUNDS IN OLDER PRESCHOOL STUDENTS WITH SEVERE SPEECH DISORDERS}

Tsyrendorzhieva Dolgor Tsydenovna Shipnyagova Olga Vasilievna Scientific adviser: Solominskaya Marina Nikolaevna

\footnotetext{
Abstract: This article about the correctional and developmental work of a speech therapist teacher in a kindergarten is the author's idea of using nontraditional means and methods for correcting sound pronunciation in preschool children. The model is based on the analysis of scientific research in the field of correctional pedagogy and speech therapy, many years of personal experience and is a holistic approach to organizing the process of correcting sound pronunciation in preschool children.
} 
Key words: speech disorders, means and methods and techniques for correcting sound pronunciation, non-traditional technologies.

Одной из ведущих линий модернизации образования является достижение нового современного качества дошкольного образования, которое учитывает социальный заказ государства и семьи на образовательные услуги, организует активное взаимодействие всех участников образовательного сообщества, направлено на формирование личности с развитым интеллектом, знанием родного языка, навыками познавательной деятельности, с высоким уровнем культуры. Правильная речь - это важнейшее условие всестороннего, полноценного развития детей.

За последние годы отмечается увеличение количества детей с речевой патологией. Многочисленные исследования [1, с. 122], [2, с. 208] и личный опыт работы [3, с. 46], [4, 500] показывают, что изменился характер речевых нарушений у детей дошкольного возраста.

Исследуя различные формы дислалии, Л.В. Мелихова [5, с 29] отмечала, что в логопедической работе при механической дислалии неблагоприятными оказываются смешанные случаи, когда кроме дефекта в строении периферического аппарата речи имеется еще и стертая форма дизартрии. Основными проявлениями дизартрии являются расстройство артикуляции звуков (речь смазанная, нечеткая), повышенная саливация и гиперкинезы, патологии голосообразования, темпа и ритма речи, нарушение общей и мелкой моторики. В таких случаях исправления речи сильно замедляется, иногда не удаётся сформировать правильное произношение всех звуков речи

Проблемой дифференциальной диагностики и методикой преодоления разных форм дизартрии занимались разные специалисты: О.В. Правдина, Е.Н. Винарская, Е.М. Мастюкова, Л.В. Лопатина, Н.В. Серебрякова, Е.Ф. Архипова и другие [6, с. $87 ; 6$, с. $268 ; 6$, с. $227 ; 6$, с. 262].

Е.Ф. Архипова [7 c. 33] подчёркивает, что для устранения стёртой дизартрии необходимо комплексное воздействие, включающее медицинское, психолого-педагогическое и логопедическое направленные на: развитие сенсорных функций; уточнения пространственных представлений; формирование конструктивного праксиса; развитие высших корковых функций; формирование тонких дифференцированных движений рук; формирование познавательной деятельности; психологическую подготовку ребёнка к обучению в школе. 
Родители часто задают вопросы: «Почему у ребенка непонятная речь и почему это происходит?». Однозначно ответить на этот вопрос сложно. Причины следует искать и в сегодняшней экологической обстановке, и в том, что, будучи беременной, будущая мама зачастую не готова к материнству.

В период беременности на развитие речевых центров плода отрицательно сказываются генетические дефекты, действия микроорганизмов и вирусов, проникающей радиации, электромагнитных и других полей. Резус конфликты, острые и хронические бытовые и производственные интоксикации, приём лекарственных препаратов, токсикозы беременных, эндогенные интоксикации на почве различных хронических заболеваний и другие, также могут оказывать негативное влияние на развитие речевых центров. Причём тяжесть речевой патологии и процессы компенсации во многом зависят от срока, на котором произошло поражение мозга. Наиболее тяжёлое поражение мозга ребёнка возникает на третьем месяце беременности.

В результате диагностического обследования артикуляционного аппарата за период с 2014 по 2020 год нами были зафиксированы следующие проценты частоты проявления у детей картины неврологического характера (рис. 1).

В 2018 году среди набранных нами в группу детей, у восьмерых воспитанников с дизартрией наблюдались дефекты в строении речевого аппарата (прогения, макроглоссия, «географический язык», разнообразные патологии подъязычной и губной уздечки).

Таблица 1

Динамика частоты неврологических отклонений у детей старшего дошкольного возраста МБДОУ детского сада №153

\begin{tabular}{|c|c|c|}
\hline Период обследования & Общее количество детей & $\begin{array}{c}\text { Дети с неврологической } \\
\text { патологией }\end{array}$ \\
\hline $2014-2016$ & 18 & $5(3 \%)$ \\
\hline $2016-2018$ & 18 & $8(5 \%)$ \\
\hline $2018-2020$ & 18 & $8(5 \%)$ \\
\hline
\end{tabular}

Для того чтобы звукопроизношение было правильным нужны сильные, упругие и подвижные органы речи - язык, губы, мягкое нёбо, зубы, верхняя и нижняя челюсти. Наиболее активный орган артикуляции язык является самым подвижным из всех перечисленных органов. Он способен занимать в ротовой полости самые разнообразные положения, образуя сближение или полное 
смыкание с органами артикуляции. Благодаря этому и образуются конкретные звуки речи.

При логопедическом обследовании органов артикуляционного аппарата отмечаем наличие и общий характер имеющихся у ребёнка аномалий анатомического строения: зубов (двойной ряд зубов; отсутствие зубов; редкие, очень мелкие или крупные зубы; неправильная форма, расположение зубов (рис. 1, рис. 2), челюстей (верхней, нижней) (рис. 3), прикуса, языка (короткая, укороченная, толстая, утолщённая подъязычная уздечка; наличие послеоперационного узла) (рис.4-7); твёрдого неба (высокое; «готическое»; низкое, плоское; наличие расщелин, мягкого нёба (нормальное или укороченное; отсутствие, укорочение, раздвоение маленького язычка; рубцовые изменения); носоглотки, ротовой полости и глотки (носовые полипы; аденоиды; искривление носовой перегородки; гипертрофия носовых раковин); губ (тонкие, утолщённые, укорочение верхней, расщелина верхней губы; укороченная уздечка верхней или нижней губы).

Мезиальный прикус (прогения) - значительное выступление подбородка вперед относительно нормы. При укороченной уздечке язык в состоянии физиологического покоя не способен занимать правильную позицию. В результате не обеспечивается необходимого давления языка на свод верхней челюсти изнутри, под действием которого в норме должен формироваться правильный купол нёба и ровный верхний ряд. Нарушение мышечного баланса ведет к избыточному давлению мышц щек и губ, вызывающему смещение верхних резцов в нёбном направлении и чрезмерный рост нижней челюсти в результате давления языка на ее передний участок. С другой стороны, ограничение подвижности языка ведет к гипертрофированному развитию мышц его корня, способствующему чрезмерному росту миндалин - причине гнусавости. 


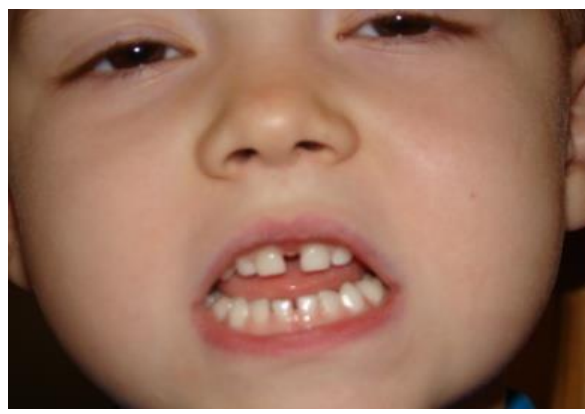

Рис. 1. Смещение передних зубов к средней линии

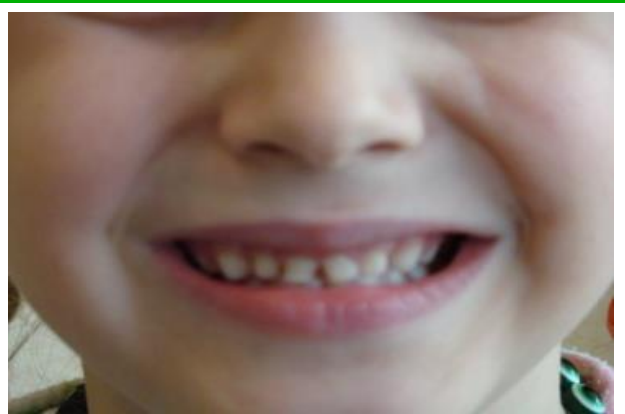

Рис. 2. Смещение передних зубов от средней линии
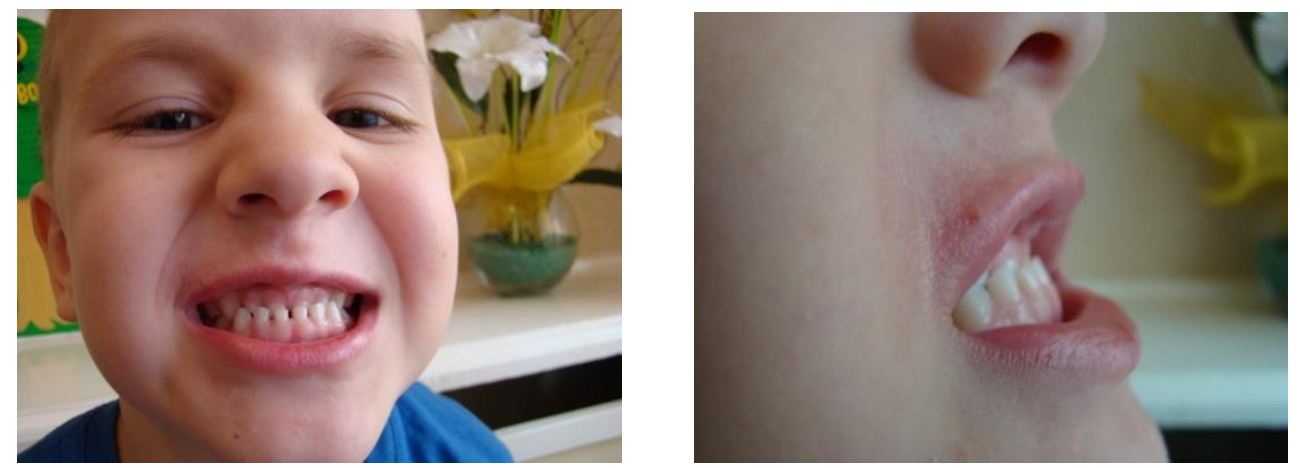

\section{Рис. 3. Мезиальный прикус}

Речевые нарушения, обусловленные поражением нервной системы, трудны в коррекции, самостоятельное восстановление их функции невозможно и требуют более длительной по времени коррекционной работы.

По наблюдениям логопедов-практиков, а также по опыту собственной логопедической работы, традиционный комплекс упражнений, используемый для коррекции звукопроизношения недостаточен для формирования или восстановления функции отдельных мышц артикуляционного аппарата.

В специальных журналах, методических и научно-популярных изданиях дефектологи, учителя-логопеды представляют новые нетрадиционные формы работ с детьми-логопатами в дополнении к академическим методам. 


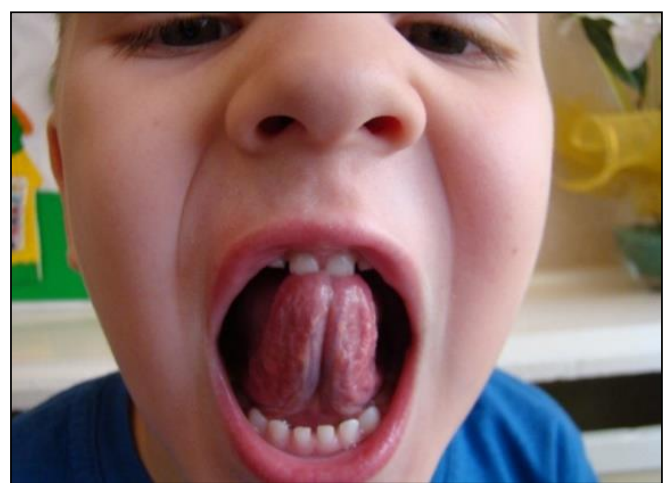

Рис. 4. Уздечка в виде тяжа, волокна которой переплетаются с мышцами языка, ограничивая его подвижность

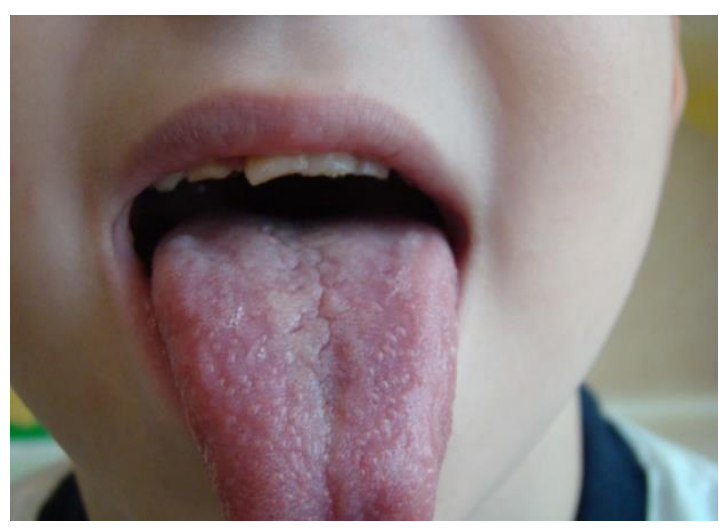

Рис. 6. Макроглоссия - чрезмерно большой язык. И так называемый "географический" язык

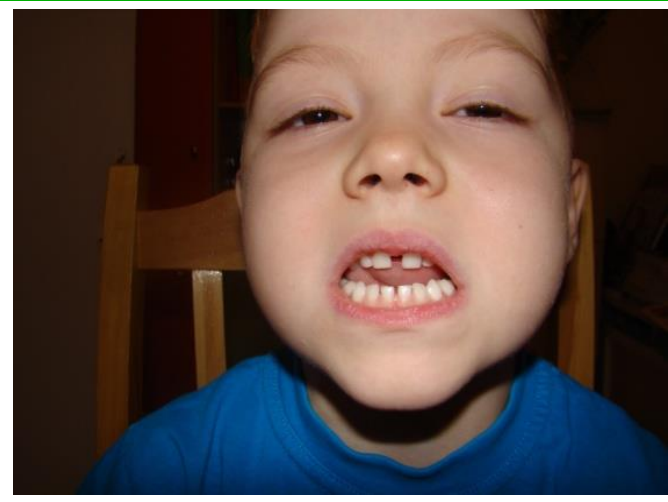

Рис. 5. Парез мышц языка, отклонение кончика в правую сторону. Укороченная подъязычная уздечка, ограничивает подвижность и пластичность языка

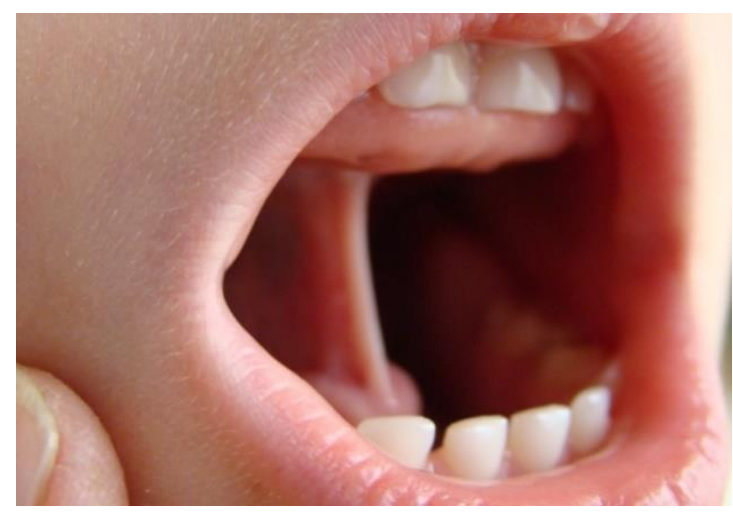

Рис. 7. Подъязычная уздечка короткий, плотный тяж, прикрепленный близко к кончику языка

Этой проблемой занимаются такие авторы как М.А. Поваляева, М.И. Чистякова, Е.А. Пожиленко, Т.Д. Зинкевич-Евстигнеева и другие. Их высказывания сводятся к тому, что использование нетрадиционных технологий оказывает наиболее эффективный результат в коррекционной работе с детьми.

Поэтому в своей работе по исправлению звукопроизношения мы попытались найти интересные и увлекательные средства коррекции. 
В сочетании с традиционной артикуляционной гимнастикой решила использовать игрушки прорезыватели для зубов.

Данные игрушки имеют разные формы, вес, размеры и различную жёсткость. Мягкие игрушки сделаны из тонкого силикона, жёсткие - из пластмассы, наполненной дистиллированной водой. Игрушки фирмы «Курносики» производятся из мягкого безопасного материала и проходят тщательный контроль качества. Они яркие, красочные по цветовой гамме, гигиеничны в использовании (рис. 8).
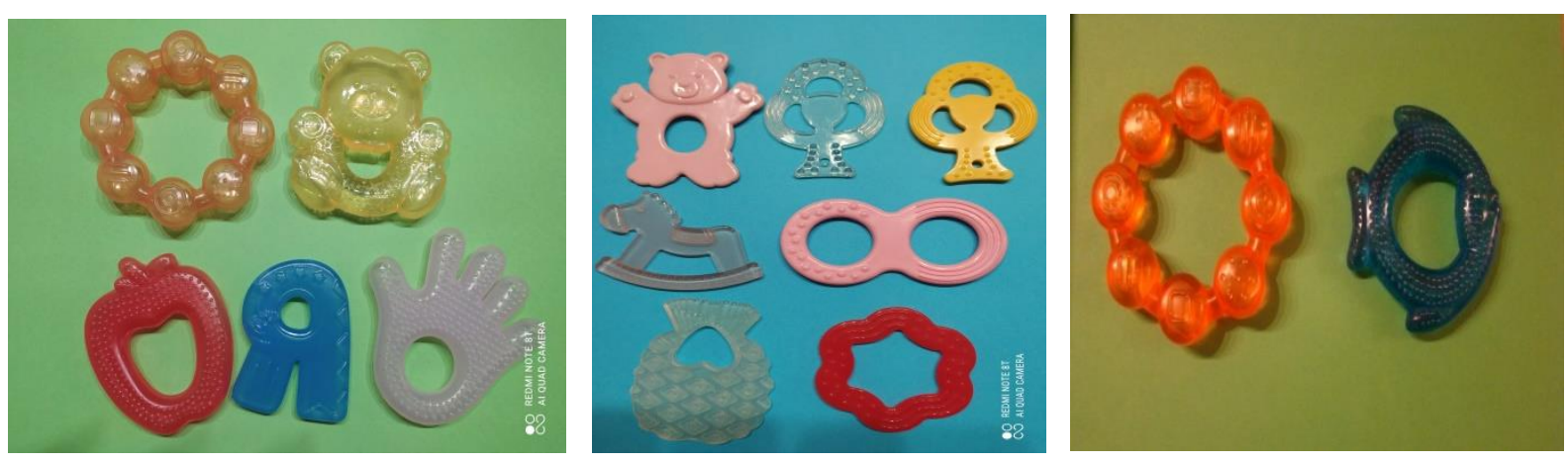

Рис. 8. Игрушки прорезыватели для зубов

Игровая ситуация позитивно влияет на эмоциональное состояние детей, способствует развитию кинестетических ощущений, снимает спазм мышц языка и развивает дополнительную его мышечную силу и тонус.

Детям нравится играть с так называемым «волшебным колесом». На поверхности колеса имеется рисунок. Дети сами определили название их изображения: ступеньки, телевизор, кочки, колесо. Кончиком языка ребенок «ощупывает» рисунок с закрытыми глазами и говорит, что это было (рис. 9).

Игрушки подобраны с изображением растительного и животного мира, что помогает на занятиях одновременно расширять словарный запас слов по лексическим темам, умение обобщать и классифицировать предметы.
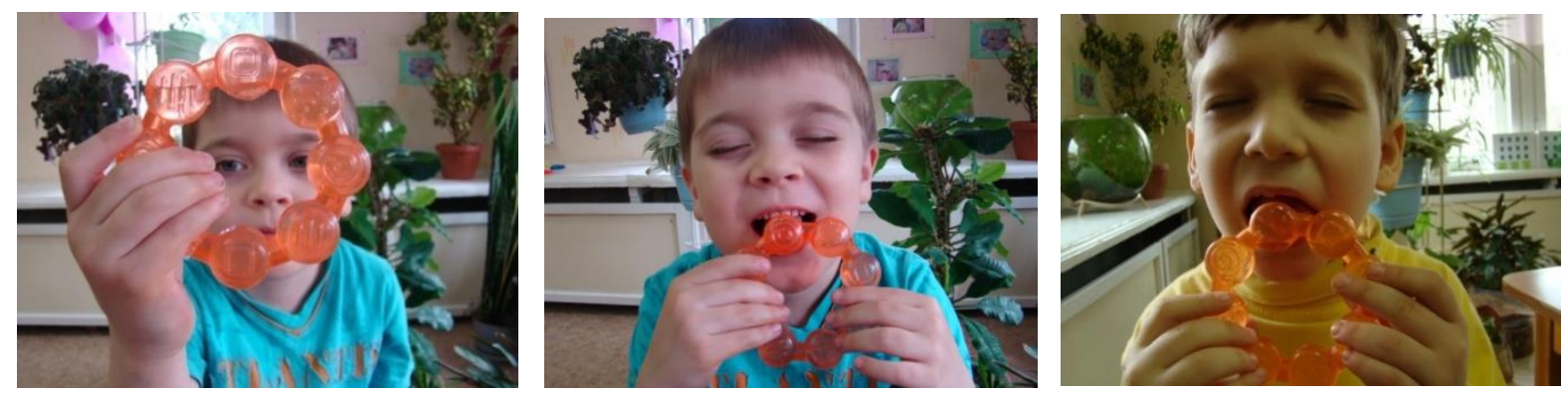

Рис. 9. Волшебное колесо 
Каждая игрушка имеет ребристую поверхность, что способствует массажу более тонких мышц языка. Повисая на кончике языка, игрушки формируют его силу и точность движений, развивают и укрепляют мышцы и тонус (рис. 10, рис. 11).
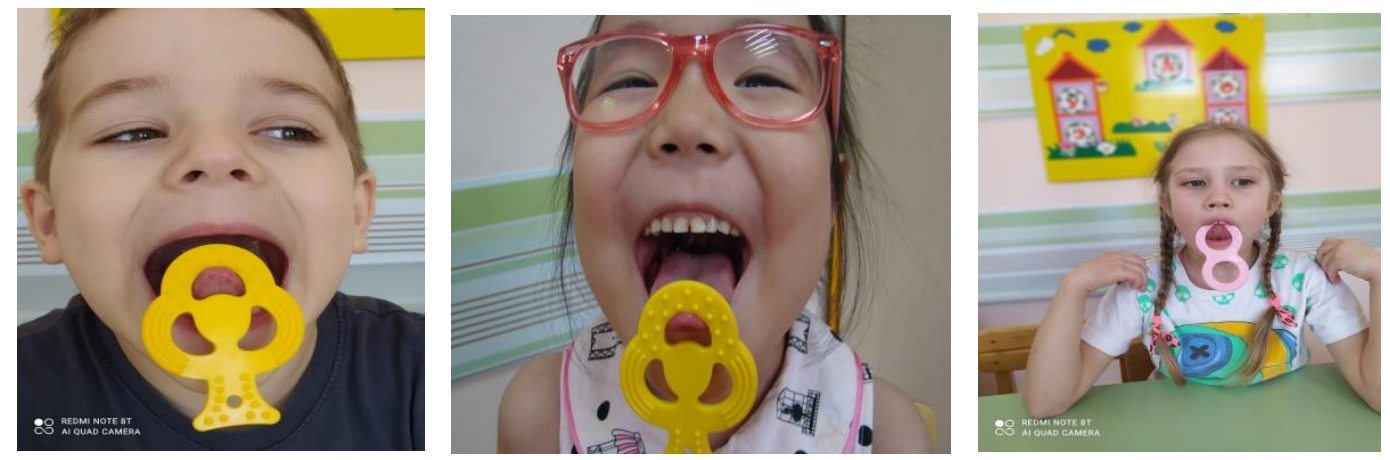

Рис. 10. Занятие с плоской игрушкой
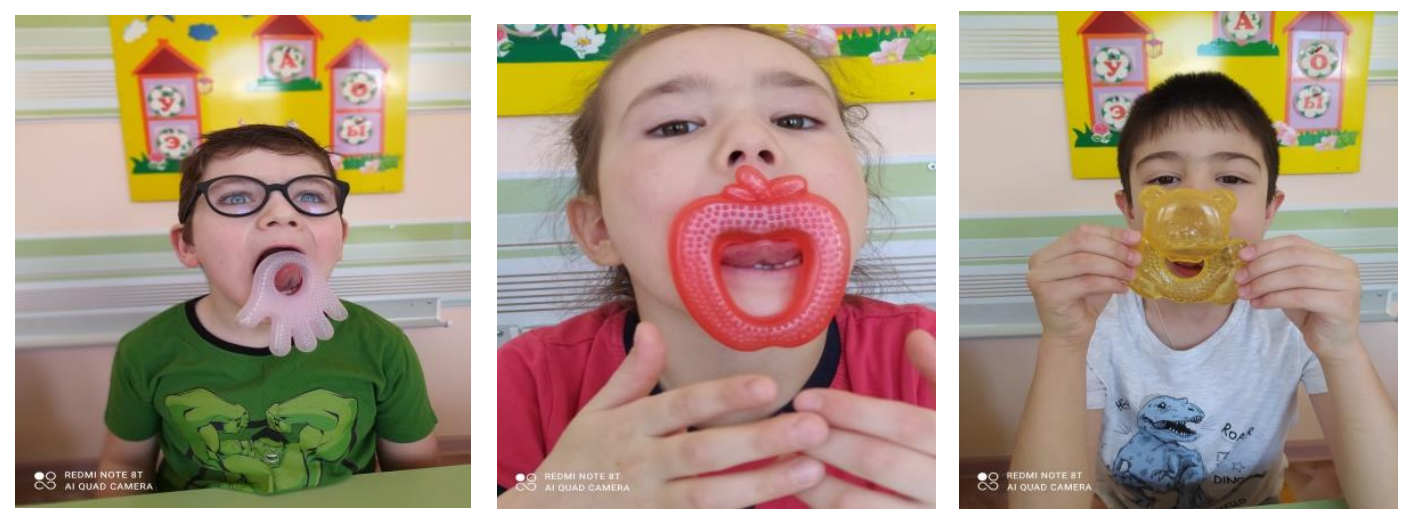

Рис. 11. Занятие с объемными игрушками

Для развития круговой мышцы рта использую плоские игрушки для прорезывания зубов. Ребенок зажимает край игрушки толщиной 2-3 мм и удерживает ее в горизонтальном положении. Для усиления сжатия губ ребенок старается удержать его и одновременно одним пальцем правой руки тянет игрушку за отверстие, которое имеется у каждого предмета. Упражнение выполняется 2 раза в день по 5 - 10 раз.

Эффективные упражнения для развития круговой мышцы рта ребёнка:

1. Придерживая руками игрушку, ребёнок сжимает и разжимает её губами -7-8 раз, при этом зубы не смыкаются. Ребристая и точечная поверхность, способствует массажу мышц верхней и нижней губы.

2. Ребёнок смыкает зубы и сжимает игрушку губами. Смыкание зубов усиливает сжатие губ. Удерживает около 30 сек до 1 минуты, после 
нескольких занятий - до 2 минут. Для контроля можно использовать песочные часы.

3. Упражнение с сопротивлением. Ребёнок зажимает игрушку губами, взрослый или сам ребёнок тянет игрушку за кольцо. Упражнения можно выполнять 2 раза в день по $7-8$ раз.

В дополнение к общепринятым артикуляционными упражнениям интересным для детей являются упражнения с шариком, диаметр 2-3 см, длина веревки 60 см, веревка продета через сквозное отверстие. Автор данных упражнений С.В. Коноваленко.

Положив шарик в рот, ребенок может перемещать его языком под левую затем правую щеку, рот закрыт (8-10 раз). Следующее задание это движение шарика языком по горизонтально натянутой на пальцах веревке вправо-влево 8-10 раз (рис.12). Затем переходим к движению шарика языком по вертикально натянутой веревке вверх. Вниз шарик падает произвольно.

Данный тренажер после каждого занятия тщательно промыть в теплой проточной воде с детским мылом и просушить салфеткой. Шарик должен быть строго индивидуальным и хранится в пластиковом контейнере. Приобретать мелкие игрушки и шарики (детские погремушки) необходимо в специализированных магазинах, имеющих сертификат качества продукции.
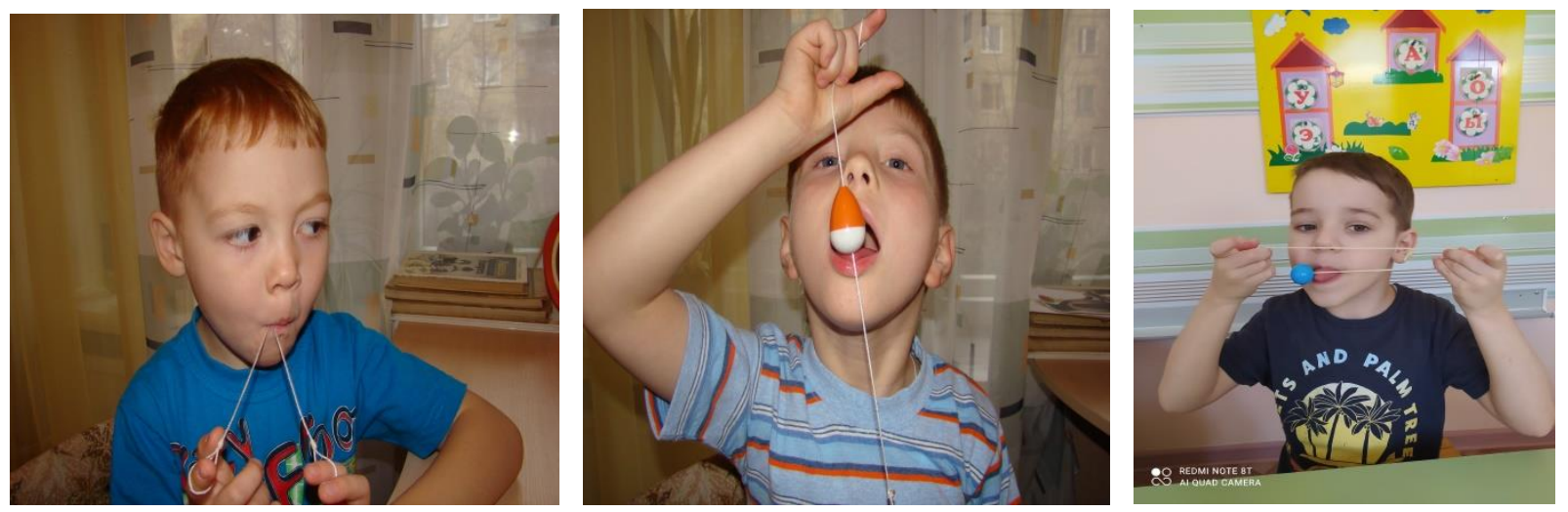

Рис. 12. Игры с шариком

Авторская идея практики заключается во внедрении в логопедическую деятельность нетрадиционных технологий; точнее использование игрушек прорезывателей для зубов, что даёт дополнительную возможность компенсировать нарушения в работе артикуляционного аппарата дошкольников, предупредить вторичные отклонения.

С большим интересом дети, проигрывая логопедические сказки для язычка, выполняют артикуляционную гимнастику. При её проведении 
большое значение имеет тактильная стимуляция, развитие статических и динамических ощущений. На начальном этапе использую более сохранные анализаторы: зрительный, слуховой и тактильный. Некоторые упражнения провожу с закрытыми глазами, привлекая внимание детей к проприоцептивным ощущениям. Детей привлекает игровой момент использования игрушек прорезывателей для зубов. Предлагаемые упражнения просты и доступны, не требуют ни специальной подготовки, ни сложного оборудования и могут использоваться для индивидуальной работы с детьми не только логопедом, педагогами, но и родителями.

Оптимальность подбора дидактических средств для достижения результатов коррекции речевых нарушений у дошкольников с дизартртией обеспечивает психологический комфорт во время занятий, позволяет развитие артикуляционной моторики, уверенную автоматизацию исправленных звуков в самостоятельной речи.

Практическая значимость данного опыта заключается и в том, что представленная информация может быть использована всеми специалистами, работающими с детьми в целях координации деятельности при решении коррекционно-развивающих и воспитательно-образовательных задач.

Практика показывает, что если не оказать своевременно детям с нарушениями речи помощь, то они начинают стесняться, бояться выступать на праздниках, отказываются отвечать на занятиях, возникают трудности при подготовке к обучению грамоте. Все эти нарушения вызывают трудности в общении с окружающими.

Создание единой образовательно-коррекционной среды, осознанное включение родителей, воспитателей, психологов, ортодонтов и стоматологов в совместный с учителем-логопедом процесс по исправлению недостатков речи у ребенка, поможет добиться высоких результатов.

Предлагаемые упражнения просты и доступны, не требуют ни специальной подготовки, ни сложного оборудования и могут использоваться для индивидуальной работы с детьми не только логопедом, педагогами, но и родителями. Следует помнить, что предлагаемые упражнения не исключают и не заменяют классических общепринятых артикуляционных упражнений. Наоборот, они закрепляют, дополняют приобретенные в процессе коррекционной работы навыки в условиях приближенных к игровой деятельности ребенка. 
Применение данных пособий поможет сформировать интерес у дошкольников к артикуляционным упражнениям; с помощью игровых ситуаций позитивно влиять на эмоциональное состояние детей, способствовать развитию кинестетических ощущения, снятию спазм мышц языка, развитию мышечной силы и тонуса; ускорить процесс постановки и автоматизации правильного звукопроизношения; совершенствовать артикуляционную моторику у детей-логопатов; сформировать интерес к слову, расширять словарный запас и кругозор; организовать детское сотрудничество.

Организованные учебные игры служат мостиком для перехода от дошкольного к школьному возрасту, что способствует сохранению психического и физического здоровья детей.

\section{Список литературы}

1. Галкина Е.А. Проблемы преемственности речевых нарушений у детей дошкольного и школьного возраста // Логопед. - № 7. - 2014. C. $122-124$.

2. Соботович Е.Ф., Чернопольская А.Ф. Проявление стертых дизартрий и методы их диагностики // Хрестоматия по логопедии (извлечения и тексты) / под ред. Л.С. Волковой и В.И. Селиверстова - М.: Гуманитарный издательский центр ВЛАДОС, 1997. - С. 208 - 213.

3. Цырендоржиева Д.Ц. Пособия и материалы для постановки звуков у детей старшего дошкольного возраста // Дошкольная педагогика. - № 3. 2016. - С. 46-47.

4. Цырендоржиева Д.Ц. Разнообразие логопедических средств в коррекции звукопроизношения у старших дошкольников с дизартрией // Современное содержание дошкольного образования: вариативность, инициатива, устойчивое развитие (Сборник научных статей по обобщению педагогического опыта). - Иркутск: МЦПТИ «Микс», 2016. - С. 500-503.

5. Мелихова Л.В. Дифференциация дислалий // Очерки по патологии речи и голоса. Вып III. - М.: Просвещение, 1967. - С.77-97.

6. Хрестоматия по логопедии (извлечения и тексты): Т1/ под ред. Л.С. Волковой и В.И. Селиверстова - М.: Гуманитарный издательский центр ВЛАДОС, 1997. $555 \mathrm{c.}$

7. Архипова Е.Ф. Стертая дизартрия у детей. - М.: АСТ: Астрель: ХРАНИТЕЛЬ, 2007. - 319 с. 